\title{
Penerapan Augmented Reality dengan Metode Marker Based Tracking pada Maket Rumah Virtual
}

\author{
Asyraful Insan Asry ${ }^{* 1}$ \\ ${ }^{1}$ Prodi Informatika, Fakultas Teknik, Universitas Muhammadiyah Makassar \\ e-mail: asyraful@unismuh.ac.id ${ }^{*}$
}

\begin{abstract}
The object of research was carried out on the model house as a virtual model that was applied to the housing brochure. Virtual mockups are created with the Artoolkit 2.7 software library to produce Augmented Reality objects with the Marker Based Tracking method. Tests carried out by making a different marker patterns of 6 types and directed webcam camera. The results of these tests, the symmetrical pattern marker model produces objects that often change position by themselves, while the pattern marker models that more often display objects do not match the model of the house being made. From the total number of marker patterns that were issued only 4 types of marker patterns were detected properly
\end{abstract}

Keyword: Augmented reality; Marker Based Tracking; Artoolkit 2.7; Virtual House Model; residential brochure

Abstrak
Objek penelitian dilakukan pada model rumah sebagai maket virtual yang diterapkan pada brosur perumahan. Maket virtual dibuat dengan software library Artoolkit 2.7 untuk menghasilkan objek Augmented Reality dengan metode Marker Based Tracking. Pengujian dilakukan dengan membuat pola marker yang berbeda sebanyak 6 jenis dan diarahkan didepan kamera webcam. Hasil dari pengujian tersebut, model pola marker yang simetris dihasilkan objek sering berganti posisi dengan sendirinya, sedangkan model pola marker yang sejenis sering menampilkan objek tidak sesuai model rumah yang seharusnya. Dari seluruh jumlah pola marker yang diuji hanya 4 jenis pola marker dideteksi dengan baik.

Kata kunci: Augmented reality; Marker Based Tracking; Artoolkit 2.7; Maket Rumah Virtual; Brosur Perumahan

\section{Pendahuluan}

Augmented Reality adalah suatu lingkungan yang memasukkan objek virtual 3D kedalam lingkungan nyata. Sistem ini lebih dekat kepada lingkungan nyata (rea). Karena itu, unsur reality lebih diutamakan pada sistem ini. Sistem ini berbeda dengan virtual reality yang sepenuhnya merupakan virtual environment (VR). Augmented Reality (AR) mengijinkan penggunanya untuk berinteraksi secara real-time dengan sistem. Penggunaan AR saat ini telah melebar ke banyak aspek didalam kehidupan kita dan terus mengalami perkembangan yang signifikan. Hal ini dikarenakan penggunaan AR sangat menarik dan memudahkan penggunanya dalam mengerjakan sesuatu hal, seperti contohnya pada strategi pemasaran dan pengenalan produk kepada konsumen.

Ketika diadakan pameran rumah, selama ini para pengusaha properti harus membuat miniatur/maket rumah agar para pengunjung bisa mengetahui secara langsung rumah yang akan mereka beli. Dengan memanfaatkan teknologi AR, miniatur rumah dapat digantikan dengan model rumah 3D yang ditampilkan secara virtual menggunakan perangkat komputer, sehingga para pengusaha dapat menghemat biaya karena mereka tidak perlu lagi membuat banyak miniatur rumah. Tidak hanya pembeli dapat melihat bagian dalam rumah dengan detil, tetapi lingkungan disekitar rumah juga akan terasa lebih hidup dengan adanya animasi pendukung seperti mobil yang melintas, pepohonan dan lain sebagainya.

Sejak era tahun 2004 hingga sekarang perkembangan bisnis properti atau usaha perumahan cenderung menunjukkan perkembangan yang pesat dibandingkan tahun-tahun 


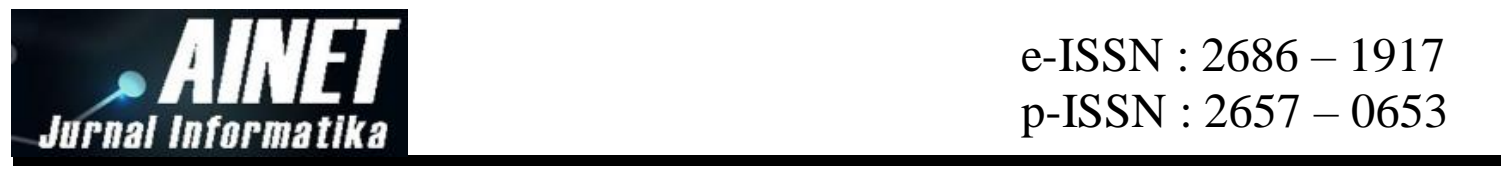

sebelumnya. Hal tersebut disebabkan oleh tingkat pertumbuhan ekonomi masyarakat yang kian membaik serta ditunjang oleh pengembang dalam membantu pemerintah dengan kesadaran sikap profesionalismenya sehingga pengadaan fasilitas hunian baik di wilayah perkotaan maupun pedesaan bisa tercapai [1].

Pada tahun 2006 transaksi penjualan perumahan di beberapa daerah di Indonesia turun, salah satu akibatnya adalah turunnya minat masyarakat yang disebabkan pengggunaan promosi dan periklanan yang belum bisa menarik pelanggan dan kondisi ekonomi nasional yang kurang baik membawa dampak yang sangat besar terhadap laju pertumbuhan bisnis property di Indonesia sehingga harus memperhitungkan cost untuk biaya promosi pada masa sekarang ini naik dengan cepat karena bahan baku yang digunakan meningkat [2]. Dengan adanya penurunan penjualan rumah maka perlu meningkatkan promosi dan periklanan dengan harga yang tidak mahal, lebih menarik dan interaktif lagi.

Penelitian sebelumnya yang berhubungan dengan penelitian ini, diantaranya E-Layout Berbasis 3D - Suatu Alternatif E-Commerce Yang Inovatif penelitian ini membahas tentang teknologi realitas virtual (virtual reality) ke dalam aplikasi elektronik commerce atau disingkat $e$ commerce yang inovatif. Untuk meningkatkan kualitas layanan kepada konsumen sebelum memutuskan untuk membeli [3]. Brosur Interaktif Berbasis Augmented Reality yang membahas tentang membuat aplikasi menggunakan media brosur yang telah diberi marker sebagai alat peraga yang diidentifikasi menggunakan kamera webcam untuk memunculkan sebuah objek 3D melalui layar monitor menggunakan Open GL [4]. Tsunami Augmented Reality : Interaksi Berbasis Marker Sebagai Pointer yang membahas tentang penggunaan marker sebagai pointer pada sistem AR tsunami memberikan kemudahan kepada pengguna untuk melakukan interaksi secara alami dan intuitif, AR tsunami sebagai salah satu media pembelajaran berbasis game dapat menjadi media alternatif untuk memperkenalkan proses terjadinya tsunami kepada pengguna, dan sistem interaksi AR tangible menawarkan gaya interaksi alami yang sesuai digunakan untuk aplikasi pendidikan, seperti pengenalan tsunami di museum.

\section{Metode Penelitian}

Jenis penelitian yang dilakukan dengan deskriptif, penelitian deskriptif merupakan metode penelitian yang berusaha menggambarkan dan menginterpretasi objek sesuai dengan apa adanya. Pada eksperimen yang dilakukan, digunakan media cetak iklan brosur untuk pameran yang telah disisipi marker, eksperimen dengan brosur bertujuan untuk menampilkan model rumah yang akan ditawarkan kepada pelanggan. Adapun metode pengumpulan data dilakukan dengan cara library research, yaitu pengumpulan data referensi yang berasal dari buku, jurnal atau hasil dari penelitian sebelumnya dan cara Field research yaitu melakukan pengamatan secara langsung di lokasi penelitian terhadap objek yang akan diteliti dan dibahas serta mengumpulkan data atau informasi sebanyak mungkin yang berhubungan dengan masalah yang akan diteliti.

Metode Augmented Reality yang digunakan yaitu Marker Based Tracking, yaitu Marker dengan ilustrasi hitam dan putih persegi dengan batas hitam tebal dan latar belakang putih [5]. Komputer akan mengenali posisi dan orientasi marker dan menciptakan dunia virtual 3D yaitu titik $(0,0,0)$ dan 3 sumbu yaitu $X, Y$,dan $Z$ seperti pada gambar 1 .
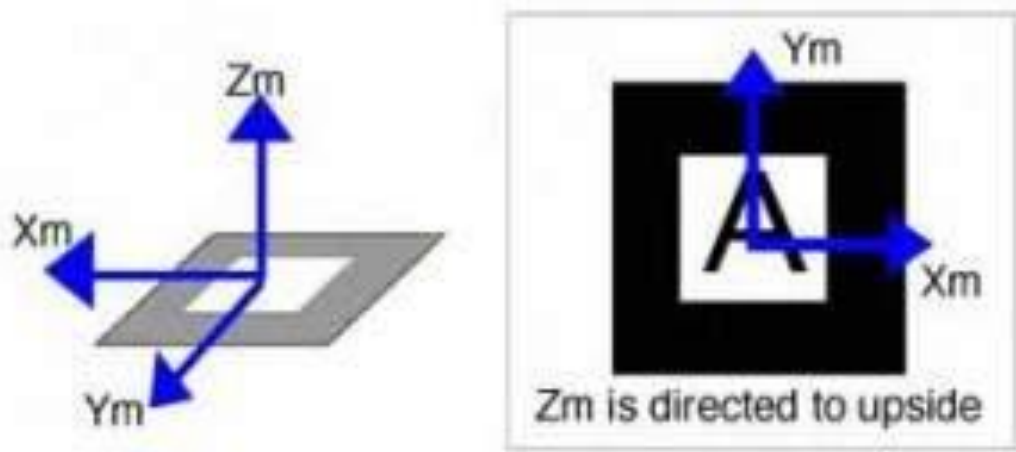

Gambar 1. Marker Based Tracking 


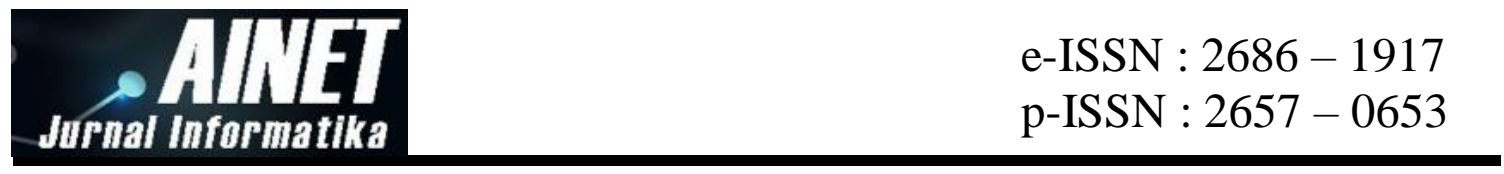

Untuk menerapkan metode Marker based tarcking dibutuhkan software library yaitu, Artoolkit. Software tersebut bekerja dengan menggunakan pelacakan video untuk menghitung posisi kamera yang nyata dan mengorientasikan pola pada kertas marker secara realtime. Setelah, posisi kamera yang asli telah diketahui, maka virtual kamera dapat diposisikan pada titik yang sama, dan objek 3D dapat digambarkan diatas marker [6].

Proses cara kerja Artoolkit terdiri dari lima langkah yaitu, Pertama kamera, mencari marker, kemudian marker yang dideteksi dirubah menjadi binary, kemudian black frame atau bingkai hitam terdeteksi oleh kamera. Langkah kedua adalah, kamera menemukan poisis marker 3D dan dikalkulasikan dengan kamera nyata. Langkah ketiga, kamera mengindentifikasi marker, apakah pola marker sesuai dengan templates memory. Langkah ke empat, dengan mentrasformasikan posisi marker. Langkah kelima, objek 3D di render diatas marker. Pada gambar 2 diperlihatkan proses cara kerja Artoolkit [7].

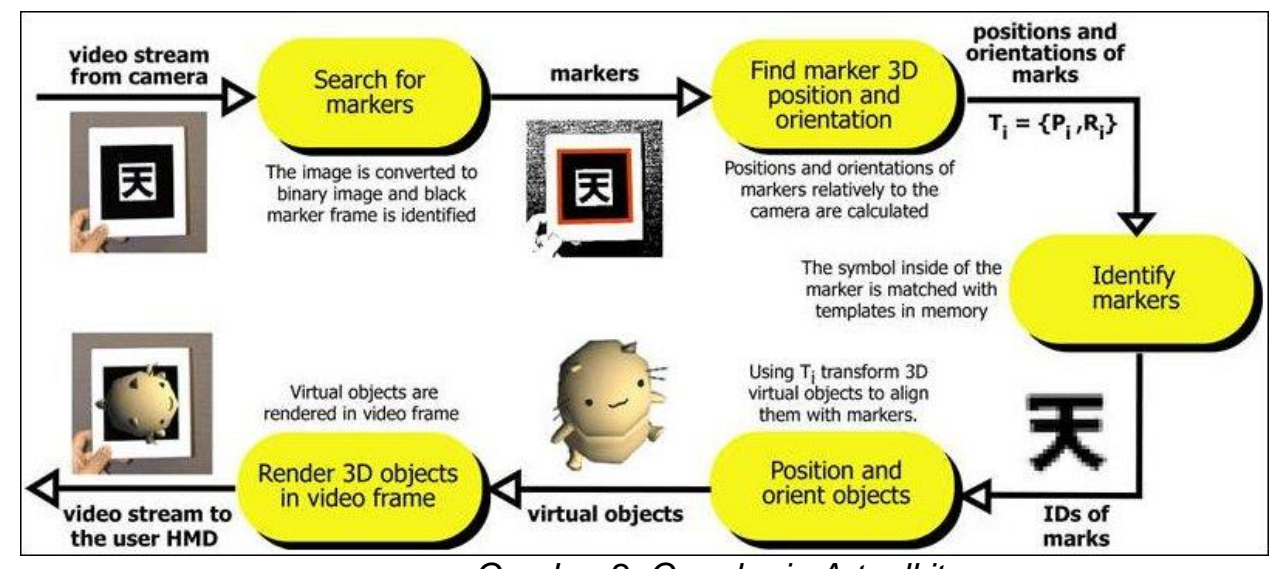

Gambar 2. Cara kerja Artoolkit

Perancangan aplikasi Augmented Reality dimulai dengan membuat flowchart untuk mengetahui cara kerja aplikasi AR terhadap model maket rumah pada brosur. Pada gambar 3 ditampilkan flowchart aplikasi. 


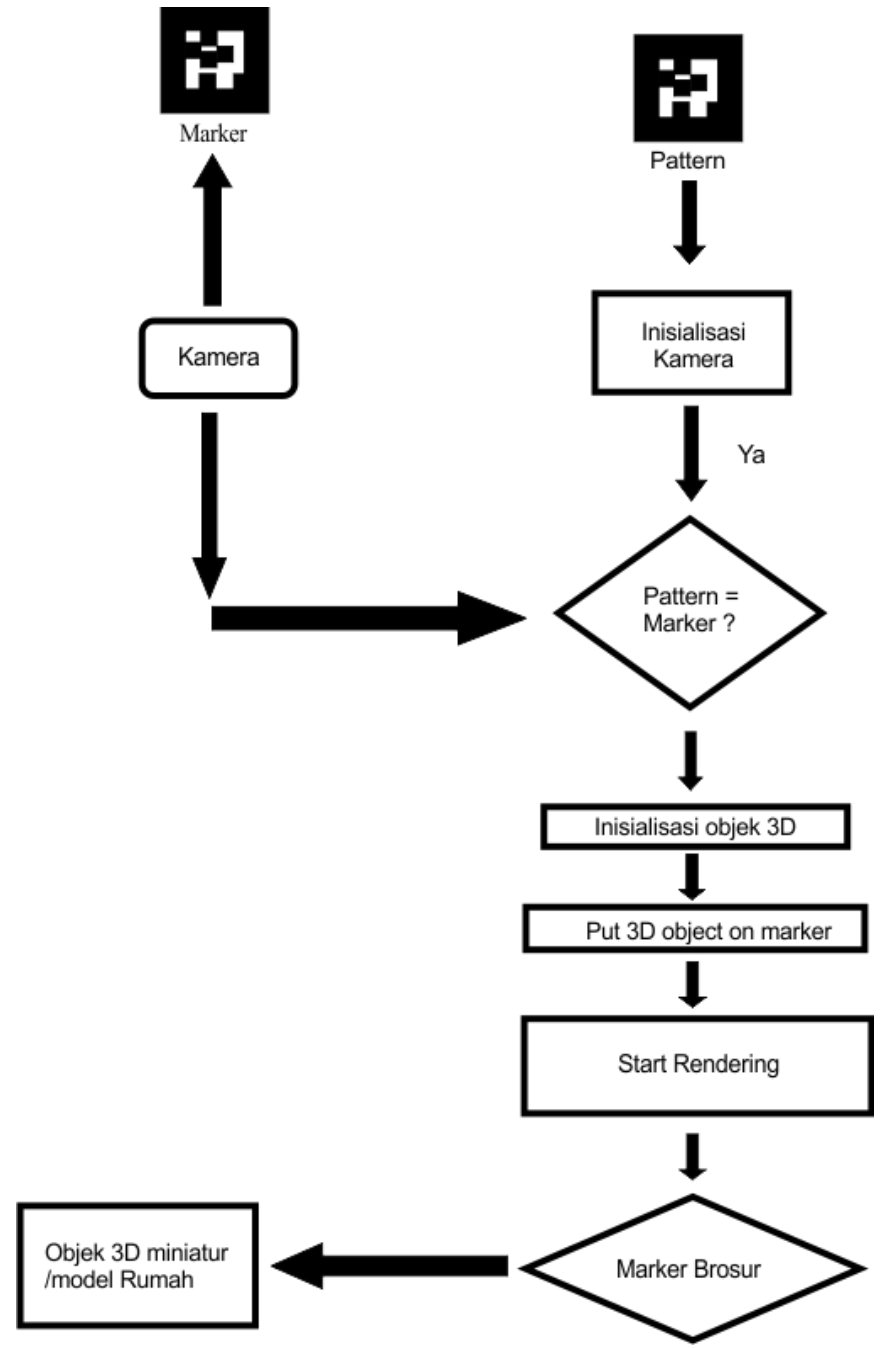

Gambar 3. Flowchart Aplikasi Augmented Reality Maket Rumah pada Brosur

Gambar 3 menunjukkan aplikasi Augmented Reality maket rumah pada brosur. Marker yang ada pada brosur dibaca oleh kamera dan diinisialisasi sesuai dengan pattern. Aplikasi akan menginisialisasi 3D sesuai dengan pattern yang terbaca dan memanggilnya diatas marker. Kemudian Aplikasi memulai merendering model objek 3D diatas marker pada brosur.

Model rumah sebagai maket virtual dibuat dengan software Archicad 12, untuk membuatnya terlebih dahulu membuat modeling nya sebagai proses tahap pertama, pada poses modeling dilakukan dengan membuat gambar denah rumah 2 dimensi dan menghasilkan objek 3D model rumah dengan tampilan perspective seperti pada gambar 4 . 


\begin{tabular}{ll} 
Jurmal informatika & e-ISSN : $2686-1917$ \\
sthe & p-ISSN : $2657-0653$ \\
\hline
\end{tabular}

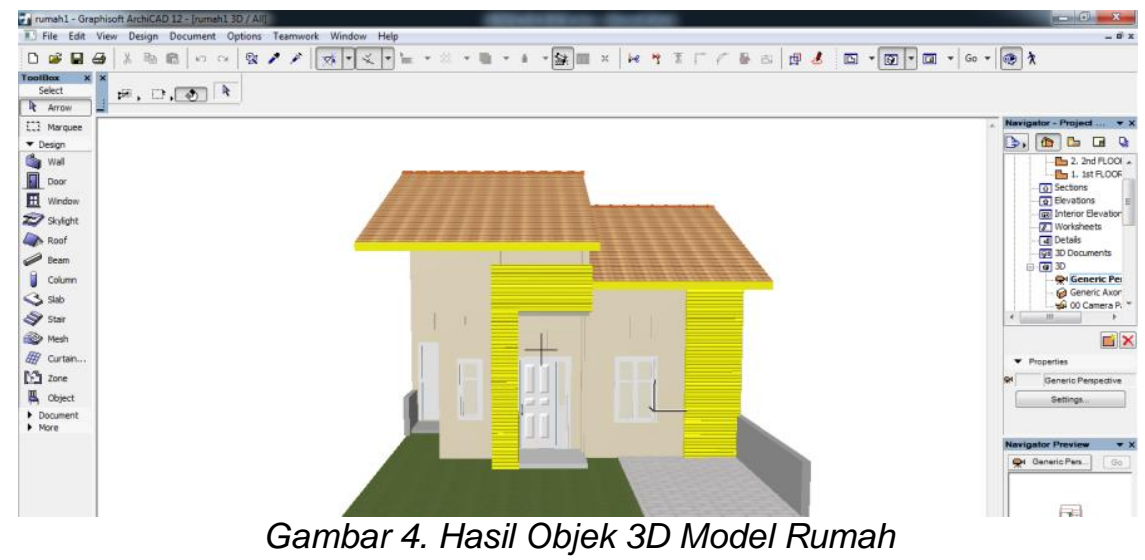

Selanjutnya pada tahap kedua dilakukan proses texturing, texturing dilakukan pada software aplikasi 3Ds MAX 2010 dengan mengubah format file menjadi * 3 ds. karena memiliki mapping untuk tekstur suatu objek dan sampel teksturnya diambil dari program ArchiCAD.

Setelah dilakukan proses teksturing dilanjutkan dengan proses Animating, yaitu proses pemberian efek gerak pada objek 3D atau proses animasi pada setiap bagian model rumah. Model yang dianimasikan adaah pada bagian atas, yaitu pada atap rumah. Setelah tahap animating dilanjutkan dengan tahap eksporting, yaitu mengubah format model 3D menjadi format *.WRL yang digunakan pada aplikasi program ARToolkit.

Untuk dapat ditampilkan pada brosur perumahan, dilakukan pembuatan model marker pada brosur permuahan. Marker berfungsi sebagai medium untuk menampilkan objek 3D pada aplikasi ARToolkit. Model marker dibuat pada aplikasi Photoshop dan disisipkan pada desain layout brosur. Pada gambar 5 ditampilkan hasil desain layout brosur setelah disisipkan marker.

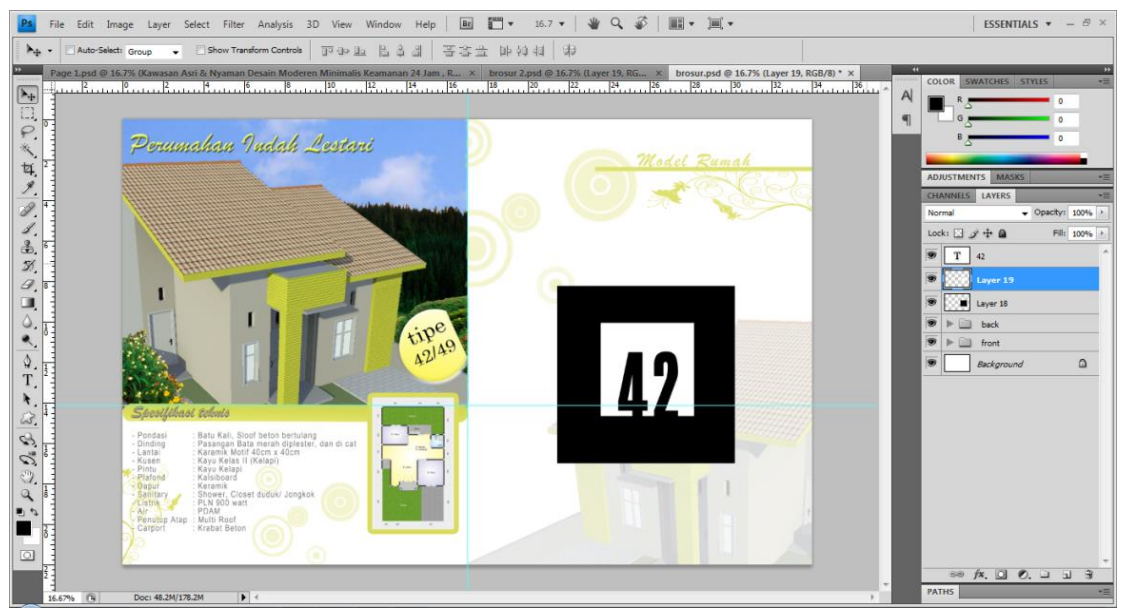

Gambar 5. Layout brosur dengan sisipan marker

\section{Hasil dan diskusi}

Setelah dilakukan pembuatan objek 3D dilanjutkan proses memasukkan data objek pada software library Artoolkit. Objek 3D yang telah dibuat Software dengan Archicad dan 3DsMax di export ke format *WRL. Selanjutnya dimasukkan file objek 3D ke dalam Artoolkit/bin/Wrl.

Pada folder aplikasi ARToolkit/bin/Wrl, pilih file berekstensi * .dat dan copy-paste file tersebut tetap didalam folder Wrl dan mengganti nama filenya sesuai nama file objek 3D rumah dengan ekstensi *.Wrl. Selanjutnya buka file berekstensi ${ }^{*}$.dat dengan aplikasi Wordpad dan ubah barisan source code databasenya sesuai nama file objek 3D berekstensi * Wrl. Setelah database *.dat telah dirubah, selanjutnya mengubah isi file database utama dengan nama object_data_vrml pada folder ARToolkit/bin/Data, buka file tersebut dengan aplikasi Wordpad. Database ini berfungsi untuk membaca file .Wrl yang sudah disisipkan di file dat yang 


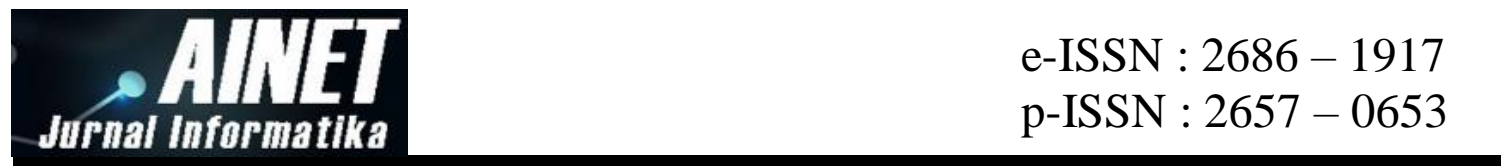

sebelumnya sudah dibuat. Database ini juga berfungsi untuk membaca pattern marker yang ingin digunakan. Dan file object_data_vrml juga bisa mengatur berapa banyak file yang ingin dirender di kamera.

Pengujian ini dilakukan untuk menguji jenis pola marker yang dapat dikenali kamera dengan baik, yang terdiri dari enam jenis pola marker seperti pada gambar 6 sebagai kasus pengujian.

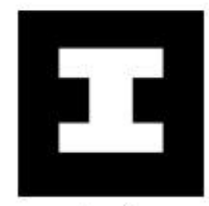

(a)

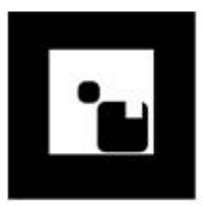

(d)

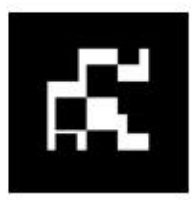

(b)

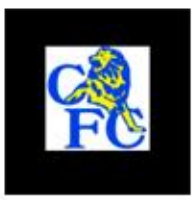

(e)

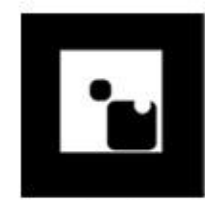

(c)

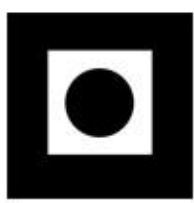

(f)

Gambar 6. Pola Marker Uji

Setelah dilakukan pengujian setiap jenis marker maka hasil yang didapatkan marker (a) dan (f) model objek yang dihasilkan diatas marker sering berganti posisi dengan sendirinya karena disebabkan marker yang simetris sehingga kurang dapat menentukan arah dan posisi model. Kesalahan ini dapat dihindari dengan mengganti pola marker dengan bentuk asimetris. Pada marker (c) dan (d) sering menampilkan model objek yang bukan modelnya disebabkan oleh pola dari kedua marker sangat mirip sehingga menimbulkan kesalahan ketika proses pengenalan marker.

\subsection{Sub bagian 1}

Masalah-masalah harus dijelaskan secara umum untuk spesifik yang ditulis secara sistematis. Referensi yang relevan harus digunakan untuk menggambarkan setiap masalah. Setiap referensi yang digunakan harus ditulis di bibliografi atau bagian Referensi dan setiap referensi yang ditulis di bagian Referensi harus dikutip dalam teks utama.

\subsection{Sub Section 2}

Setiap paragraf terdiri dari satu kalimat utama dan beberapa kalimat penjelas. Penjelasan harus disampaikan secara sistematis dan memberikan informasi tentang bagaimana penulis melakukannya, terkait dengan data, metode, atau tahapan yang dilakukan.

\section{Kesimpulan}

Pengujian model marker yang telah dilakukan, terjadi kesalahan deteksi pada pola marker dengan model simetris. Kesalahan terjadi karena proses deteksi marker pada Artoolkit tidak mampu membedakan setiap posisi model marker sama atau simetris. Deteksi marker dengan model yang sama meskipun dengan nama file yang berbeda, terdeteksi salah dalam mengenali model objek sehingga ditampilkan model rumah yang sama. Untuk mengatasi kesalahan model marker, dilakukan pembuatan marker yang tidak simetris dan mirip atau hampir mirip.

Software Artoolkit mampu diterapkan sebagai media virtual model rumah pada brosur perumahan yang lebih interaktif kepada calon pembeli untuk mengetahui informasi yang lebih detail.. 


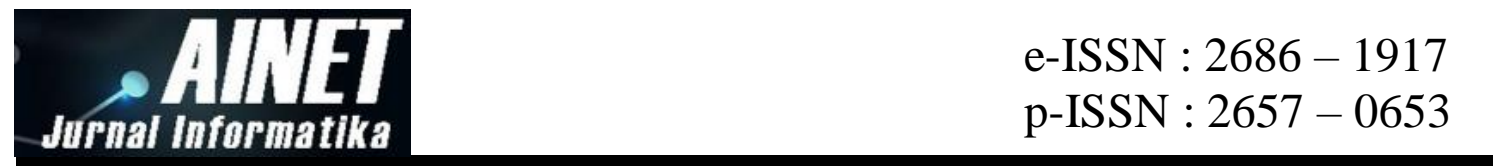

\section{Referensi}

[1] S. M. Suparno and E. Marlina, "Perencanaan dan pengembangan perumahan," Bandung Alf., 2006.

[2] S. Limanto, "EVALUASI INVESTASI PROYEK PENGEMBANG PERUMAHAN MEMAKAI MEKANISME TEKNIS ALIRAN DANA DISKONTO," J. Tek. Sipil Univ. Atma Jaya Yogyakarta, vol. 7, no. 3, pp. 203-211, 2007.

[3] A. Sutanto and B. R. S. Manufaktur, "E-Layout berbasis 3D-Suatu Alternatif e-Commerce yang Inovatif," 2010.

[4] M. Chafied, R. Hakkun, and R. Asmara, "Brosur interaktif berbasis augmented reality," EEPIS Final Proj., 2010.

[5] M. Haller, M. Billinghurst, and B. Thomas, Emerging Technologies of Augmented Reality: Interface and Design. Idea Group Publishing, 2010.

[6] M. Haller, Emerging Technologies of Augmented Reality: Interfaces and Design. London: Idea Group Publishing, 2018.

[7] 2010. [Online]. Available:

http://www.hitl.washington.edu/artoolkit/documentation/vision.htm. 